\title{
Hypertriglyceridemia Induced Recurrent Pancreatitis Case
}

Seda KARAASLAN ${ }^{1}$, Ensar AYDEMİR², Coşkun ATEŞ², Yasemin AYDOĞAN ÜNSAL ${ }^{2}$, Canan ERSOY², Özen ÖZ GÜL ${ }^{2}$, Soner CANDER², Erdinç ERTÜRK ${ }^{2}$

${ }^{1}$ Bursa Uludağ University Faculty of Medicine, Department of Internal Medicine, Bursa, Turkey

${ }^{2}$ Bursa Uludağ University Faculty of Medicine, Division of Endocrinology and Metabolic Diseases, Bursa, Turkey

\begin{abstract}
Hypertriglyceridemia is a common cause of acute pancreatitis. Metabolic syndrome can lead to the development of hypertriglyceridemia. Here we presented a pancreatitis case with type 2 diabetes, obesity, and dyslipidemia.
\end{abstract}

Turk J Int Med 2021;3(Supplement 1):S101-S103

DOI: $\underline{10.46310 / \text { tjim.885774 }}$

Keywords: Hypertriglyceridemia, acute pancreatitis, etiology, treatment

\section{Introduction}

The diagnosis of acute pancreatitis (AP) consists of the history and typical clinical criterias of the patient, serum amylase and lipase levels being 3 times the upper limit of the normal and imaging findings. The diagnosis is made based on the fact that two of these three criterias are positive. Severe AP is determined by commonly used APACHE II score 8 and Ranson score 3 . Hypertriglyceridemia (HTG) is defined as a fasting serum value above $150 \mathrm{mg} / \mathrm{dL}$. HTG is classified as mild (150-199 $\mathrm{mg} / \mathrm{dL})$, moderate (200-999 mg/ dL), severe $(1,000-1,999 \mathrm{mg} / \mathrm{dL})$ and very severe $(>2,000 \mathrm{mg} /$ $\mathrm{dL})$. When the triglyceride value is over $1,000 \mathrm{mg} /$
$\mathrm{dL}$, it poses a risk for AP. While the risk for AP above $1,000 \mathrm{mg} / \mathrm{dL}$ is $5 \%$, it is $10-20 \%$ when it is above $2000 \mathrm{mg} / \mathrm{dL} .1$ Both the acute inflammatory response of the pancreatitis itself and the lipotoxicity caused by free fatty acids formed by the breakdown of triglycerides as a result of activation of the pancreatic lipase enzyme are effective in the severity of AP. HTG is the third most common cause of acute pancreatitis after gallstones and alcohol. AP develops due to HTG at a rate of $1-4 \%$. HTG caused by disorders in lipoprotein metabolism can be due to primary (genetic) or secondary causes like alcohol use, diabetes

Received:February 24, 2021;Accepted:March 6,2021;Published Online:March 6, 2021

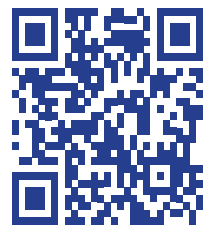




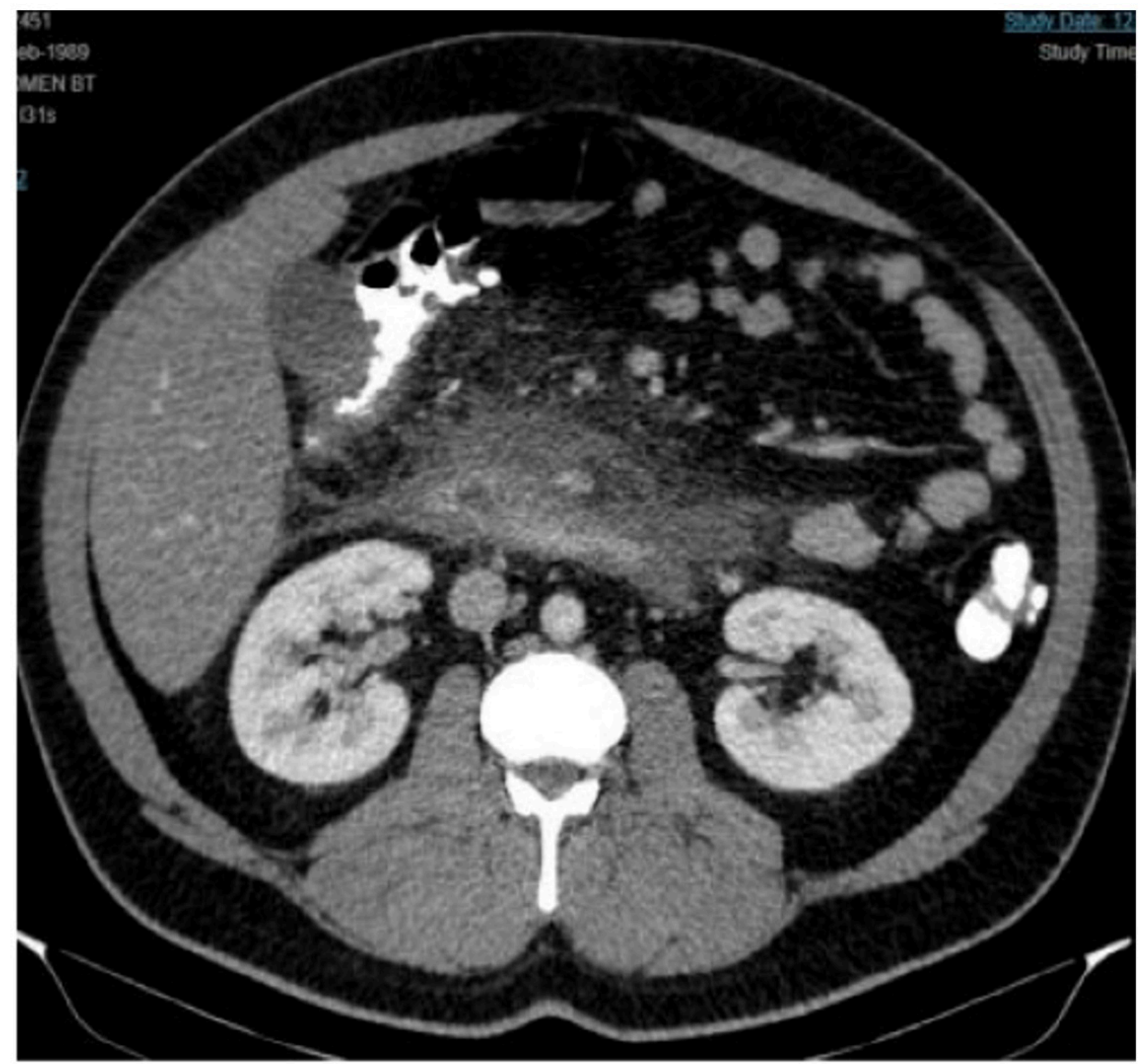

Figure 1. Patient's computed tomography indicating acute pancreatitis.

mellitus, pregnancy, obesity, hypothyroidism, nephrotic syndrome and some medications. Primary and secondary causes may coexist in patients. Metabolic syndrome is also an important factor contributing to the development of HTG. ${ }^{1-3}$ In this report, a case of AP triggered by HTG with other metabolic syndrome components like type 2 diabetes mellitus and obesity was presented.

\section{Case Report}

A 31-year-old male patient admitted to the emergency service of our center due to acute onset epigastric pain radiating to the back. His medical history included type 2 diabetes mellitus which was diagnosed 1 year ago and a previous hospitalization due to AP seven months ago. He was using his insulin glargine, insulin Aspart and fenofibrate medications irregularly. He had no alcohol use but 14 package-years of smoking in his history. His height was 180 centimeters, weight was 122 kilograms and body mass index were 37 $\mathrm{kg} / \mathrm{m}^{2}$. His body temperature was $36.7^{\circ} \mathrm{C}$, blood pressure was $110 / 70 \mathrm{mmHg}$ and pulse rate were 78 beats/minute on admission. In his physical examination, there was no pathologic feature except epigastric tenderness. He had a laboratory evaluation, in which total cholesterol was $340 \mathrm{mg} /$ $\mathrm{dL}$, triglyceride $3,117 \mathrm{mg} / \mathrm{dL}$, LDL cholesterol 211 $\mathrm{mg} / \mathrm{dL}$, amylase $131 \mathrm{mg} / \mathrm{dL}$, glucose $249 \mathrm{mg} / \mathrm{dL}$, and $\mathrm{HbA} 1 \mathrm{c} 10 \%$, all being above the normal range. There was no acidosis in the arterial blood sample. His abdominal computed tomography revealed findings of AP (Figure 1). His Ranson criteria 
was 1 point which was scored as mild pancreatitis. In his treatment 4-6 liters/day intravenous fluid mainly sodium chloride, $0.1 \mathrm{IU} / \mathrm{kg} / \mathrm{h}$ insulin infusion and $5 \%$ dextrose infusion to avoid hypoglycemia were given. In the 3rd day of his admission, his oral nutrition and diabetes mellitus treatments were regulated. His subcutaneous insulin treatment was rearranged, and infusion was stopped. Rapid triglycerides decrease and clinical improvements were observed with insulin infusion without the need for plasmapheresis. In the $8^{\text {th }}$ day of his admission, his triglyceride level was $642 \mathrm{mg} / \mathrm{dL}$, total cholesterol was $227 \mathrm{mg}$ / $\mathrm{dL}$ and serum glucose were $201 \mathrm{mg} / \mathrm{dL}$ in the laboratory tests.

\section{Discussion}

Fenofibrate and omega-3 were prescribed for HTG, a diet program was scheduled for obesity. Necessary lifestyle changes were advised. He was discharged from the hospital in the $8^{\text {th }}$ day of his admission. The pathophysiology associated with pancreatitis, one of the life-threatening acute complications of HTG, is not fully understood. The primary treatment goal in these cases is to restore triglyceride levels within normal ranges. This situation can be achieved with fluid replacement, intravenous insulin infusion and/ or plasmapheresis treatments. Plasmapheresis is a high cost and rarely used method when necessary with complications like infection and allergic reactions. In addition to these, analgesia, anticoagulation prophylaxis, lipid lowering agents (fibrates as the first choice) and supportive treatments according to the severity of pancreatitis (antibiotics, oxygen) are used. Medium chain fatty acids, omega-3-fatty acids, niacin, microsomal transport protein inhibitors and gene therapy can be used as adjuvants. ${ }^{4}$ Strict diet restricted primarily from fat and simple sugars, exercise and providing weight control also contribute to HTG control.

\section{Conflict of Interests}

Authors declare that there are none.

\section{Acknowledgment}

This study has been presented in $17^{\text {th }}$ Uludag Internal Medicine National Winter Congress, $6^{\text {th }}$ Bursa Family Medicine Association National Congress, $11^{\text {th }}$ Uludag Internal Medicine Nursing Congress, 5-7 March 2021, Bursa, Turkey.

\section{References}

1. Fortson MR, Freedman SN, Webster PD 3rd. Clinical assessment of hyperlipidemic pancreatitis. Am J Gastroenterol. 1995 Dec;90(12):2134-9.

2. Tenner S, Baillie J, DeWitt J, Vege SS; American College of Gastroenterology. American College of Gastroenterology guideline: management of acute pancreatitis. Am J Gastroenterol. 2013 Sep;108(9):1400-15. doi: 10.1038/ ajg.2013.218.

3. Zeng Y, Wang X, Zhang W, Wu K, Ma J. Hypertriglyceridemia aggravates ER stress and pathogenesis of acute pancreatitis. Hepatogastroenterology. 2012 Oct;59(119):2318-26. doi: 10.5754/hge12042.

4. Gelrud A, Whitcomb DC. Hypertriglyceridemia-induced acute pancreatitis. Uptodate 2021. Avaliable at: https://www. uptodate.com/contents/hypertriglyceridemia-inducedacute-pancreatitis. Accessed January 13, 2020 